\title{
Amide bond formation by using amino acid fluorides
}

\author{
John W. Lippert III
}

Albany Molecular Research, Inc., 21 Corporate Circle, P.O. Box 15098, Albany, NY 12212-5098 USA

E-mail: john.lippert@albmolecular.com

\section{Dedicated to Professor George R. Pettit on the occasion of his $76^{\text {th }}$ birthday}

\begin{abstract}
Amino acid fluorides have been used extensively in peptide synthesis. The following review surveys the formation and coupling of amino acid fluorides in both peptide and organic synthesis.
\end{abstract}

Keywords: Amino acid fluorides, TFFH, solution-phase peptide synthesis, solid-phase peptide synthesis.

\section{Contents}

1. Introduction

2. Formation of Amino Acid Fluorides

3. Solid-Phase and Solution-Phase Couplings

4. Hindered Amide Couplings

5. Miscellaneous Couplings

6. Appendix

7. Acknowledgement

8. References

\section{Introduction}

N-Protected amino acid chlorides have been known since the early 1900 's. ${ }^{1}$ They have been rarely used in peptide synthesis until recently when they have been successfully applied to the rapid coupling of Fmoc-amino acids. ${ }^{2,3}$ However, because of their high reactivity and sensitivity to hydrolysis, acid chlorides should be prepared from the parent amino acids immediately before 
use $^{2}$ and a large excess of reactant is typically required for their synthesis. ${ }^{3}$ Acid fluorides, on the other hand, are known to be more stable to hydrolysis than acid chlorides ${ }^{4}$ but they have been rarely used in organic synthesis because of their presumed low reactivity toward common nucleophiles. ${ }^{3}$ However, fluorides like indole 2-carbonyl fluoride have been shown to react readily with silylated aliphatic and aromatic amines. ${ }^{3,5}$

(All abbreviations not cited in the text are listed in the Appendix.)

\section{Formation of Amino Acid Fluorides}

Amino acid fluorides (AA-F) can be synthesized using two main methods as outlined below.

The first method uses cyanuric fluoride (2) as the fluorinating agent (Scheme 1). In a typical experiment, equimolar amounts of the amino acid $\mathbf{1}$, pyridine and cyanuric fluoride (2) are mixed and stirred for 3-4 hours in dichloromethane at room temperature. ${ }^{3}$ At that time, ice-water is added to the reaction mixture and the precipitated cyanuric acid (4) is filtered off. ${ }^{3}$ The organic phase is evaporated to dryness, which generally affords the pure amino acid fluoride $\mathbf{3}$ in crystalline form. ${ }^{3}$<smiles>[X]NC([R])C(=O)O</smiles>

1<smiles>Fc1nc(F)nc(F)n1</smiles>

2

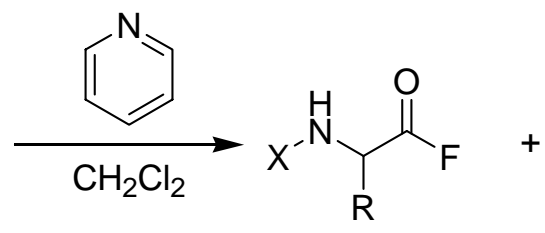

3<smiles>Oc1nc(O)nc(O)n1</smiles>

4

\section{Scheme 1}

The second method uses TFFH, 5 as the fluorinating agent (Scheme 2). TFFH is a nonhygroscopic air stable salt, that can be handled under routine conditions, ${ }^{6}$ and is available commercially. Infrared examination shows that in the presence of DIPEA, Fmoc-amino acids are converted using TFFH to the acid fluorides $3 .^{6}$ In dichloromethane solution at room temperature, an IR absorption characteristic of the carbonyl fluoride moiety $\left(1842 \mathrm{~cm}^{-1}\right)$, appears after about 3 min, with complete conversion to the acid fluoride occurring after 8-15 min. ${ }^{5}$ For hindered amino acids (e.g., Aib) complete conversion may require 1-2 h. ${ }^{6}$ If desired, the acid fluorides may be isolated and purified, making TFFH a benign substitute for the corrosive cyanuric fluoride. ${ }^{6}$

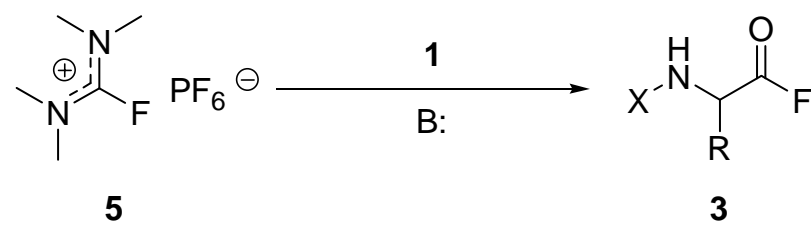

\section{Scheme 2}


Another reagent which uses the same methodology as shown above is BTFFH (Figure 1). BTFFH behaves the same as TFFH in its ability to form amino acid fluorides in both the solution and solid phase. ${ }^{7}$ The main advantage in using BTFFH over TFFH is that one does not form volatile or toxic byproducts. $^{7,8}$

Furthermore, additives such as PTF and pyridine-hydrogen fluoride reagent have been used successfully to obtain amino acid fluorides. ${ }^{9}$

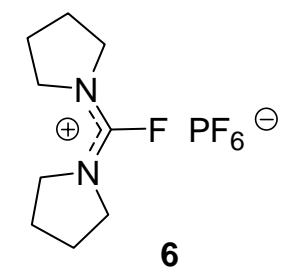

\section{Figure 1}

Protecting groups such as Fmoc, Boc, and $Z$ can be used on the $\alpha$-nitrogen of the amino acid en route to the corresponding amino acid fluorides. ${ }^{10}$ Generally the corresponding acid chlorides bearing the Boc or $t$-butyl protecting groups were either too sensitive to be isolated or were subject to facile degradation on storage. ${ }^{10}$ Z-protected amino acid chlorides have also proven not to be stable, undergoing both hydrolysis and conversion to the corresponding Leuch's anhydrides ${ }^{10}$ thereby limiting their synthetic utility. ${ }^{10} \mathrm{New}$ in situ methods for the preparation of $\mathrm{Z}$ amino acid chlorides have been described in response to the above problems. ${ }^{10}$ The $\alpha$-Fmoc, $\alpha$ Boc, and $\alpha-Z$ amino acid fluorides can be synthesized, purified, and stored for extended periods without experiencing hydrolysis. ${ }^{10}$

\section{Solid-Phase and Solution-Phase Couplings}

Amino acid fluoride couplings have been effective in both solution and solid- phase arenas. Both methods have an absence of appreciable racemization $(<1 \%)^{3,10,11}$ and are normally rapid $(<20$ min) reactions. ${ }^{3,10,11}$ Not only does the acid fluoride methodology co-exist well with acid sensitive groups (Boc and tert-butyl side chain protecting groups), but it is the unique acyl fluoride functionality itself that is likely to assure the widespread applicability of this general class of reagents. ${ }^{10,11 \mathrm{~b}}$ Due to the nature of the C-F bond, acyl fluorides are of greater stability than the corresponding chlorides toward neutral oxygen nucleophiles such as water or methanol yet appear to be of equal or nearly equal reactivity toward anionic nucleophiles and amines. $3,10,11$ Solution-phase couplings can be carried out using either of the two methods discussed below:

1. Boc-AA-F $(1.1 \mathrm{mmol})$ in $10 \mathrm{~mL}$ of $\mathrm{CH}_{2} \mathrm{Cl}_{2}$ was added over a period of 60 seconds to a stirred solution of $\mathrm{H}-\mathrm{AA}-\mathrm{OEt} \cdot \mathrm{HCl}(1 \mathrm{mmol})$ in $10 \mathrm{~mL}$ of $\mathrm{H}_{2} \mathrm{O}$ containing $\mathrm{NaHCO}_{3}(2$ mmol). The mixture was stirred for $20 \mathrm{~min}$ (after 5-10 min IR examination showed the 
acid fluoride band $1845 \mathrm{~cm}^{-1}$ to have essentially disappeared). After washing of the $\mathrm{CH}_{2} \mathrm{Cl}_{2}$ solution twice each with $5 \% \mathrm{HCl}, 10 \% \mathrm{NaHCO}_{3}$, and $\mathrm{H}_{2} \mathrm{O}$, the dried solution was evaporated in vacuo and the crude dipeptide was recrystallized from ether/hexane to give the pure dipeptide. [Yields were typically in the $65-90 \%$ range.] ${ }^{10}$

2. One phase couplings were carried out by addition of the acid fluoride in dry $\mathrm{CH}_{2} \mathrm{Cl}_{2}$ to a solution of the amino acid ester hydrochloride and 2 equivalents of diisopropylethylamine or $\mathrm{N}$-methylmorpholine in $\mathrm{CH}_{2} \mathrm{Cl}_{2}$ over a period of $60 \mathrm{~s}$. Workup followed the discussion above. [Yields were typically in the $75-90 \%$ range. ${ }^{10}$

Acid fluoride couplings have also been applied to solid-phase synthesis. In earlier work the AA-F was synthesized and then used on the solid-phase system. In recent years, the method of choice for solid-phase peptide synthesis has been to use TFFH to synthesize the AA-F in situ. TFFH is an ideal coupling reagent for solid phase syntheses, being readily available, inexpensive, and capable of providing crude peptides of high quality. ${ }^{11 \mathrm{~b}}$ An example is the assembly of peptide 7, which, due to the difficult Aib-Aib coupling, has previously ${ }^{11}$ been used to demonstrate the superiority of HATU over HBTU (Figure 2). ${ }^{11 \mathrm{~b}}$

H-Tyr-Aib-Aib-Phe-Leu- $\mathrm{NH}_{2}$

7

\section{Figure 2}

Using DMF as solvent and a Biosearch 9050 instrument programmed for 7-min preactivation, 7-min deblocking, and 30-min coupling [5-fold excess of acid, 10-fold excess of base (DIPEA)] for all amino acids except Aib-Aib, for which a 1-h double coupling was used, pentapeptide 7 was obtained in $88 \%$ yield; purity of crude product, 92\%; amount of des-Aib tetrapeptide, $4 \%{ }^{11 \mathrm{~b}}$ By contrast, under similar conditions the earlier syntheses ${ }^{12}$ HATU gave, $94 \%$ purity, and HBTU, $43 \%$ purity. ${ }^{11 \mathrm{~b}}$

Fmoc-amino acid fluorides have been used extensively on the solid-phase system, ${ }^{3,11}$ and have even been used for Multiple Peptide Synthesis (MPS) ${ }^{13}$ due to their exceptional reactivity, high solubility in organic solvents ( $>1 \mathrm{M}$ in DMF), and stability in solution over extended periods of time. $^{14}$

\section{Hindered Amide Couplings}

Fmoc-amino acid fluorides have been shown to be excellent coupling reagents for both solution and solid-phase peptide syntheses ${ }^{10 a, 15 a}$ and for the efficient acylation of hydroxyl moieties. ${ }^{16,18}$ However, their most impressive application is the coupling of adjacent sterically-hindered amino acids such as Aib as demonstrated by the first successful solid-phase synthesis of the 
peptaibols, ${ }^{17}$ naturally occurring peptides containing a high content (up to $60 \%$ ) of Aib residues. $^{18}$

The couplings of acid fluorides derived from Aib and NMe-Gly have been shown to proceed without difficulty, although problems arose when more hindered substrates were used such a Iva, NMeVal, Deg, and NMe-Aib. [Conditions: $0.5 \mathrm{mmol} \mathrm{HCl} \cdot A i b O M e, 0.55 \mathrm{mmol}$ Fmoc amino acid fluoride, 1.05 mmol DIEA, $5 \mathrm{~mL} \mathrm{DMF}]^{18}$ When the coupling rates were low, premature deblocking of the Fmoc group was observed as a prominent side reaction. ${ }^{18}$ In addition, IR studies revealed that Fmoc-amino acid fluorides derived from $\alpha, \alpha$-dialkylated species are converted slowly into the corresponding oxazolones 9 (Scheme 3) when tertiary amines are present. ${ }^{10 \mathrm{a}, 18,19}$

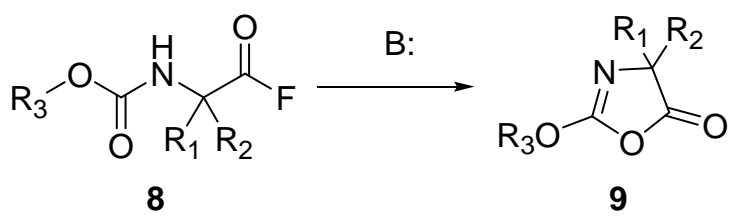

\section{Scheme 3}

It has been reported that Fmoc-amino acid fluorides could be coupled in the absence of base. ${ }^{18,20}$ Furthermore, an even more effective approach involves the prior treatment of the amino component of the coupling system with a silylating agent such as N,O-bis(trimethylsilyl) acetamide (BSA). ${ }^{18}$ Amide bonds can be formed readily under mild conditions by reaction of $N$ silylamines with acyl fluorides, ${ }^{18,21}$ even in the case of sterically hindered secondary amines. ${ }^{18,22}$ By treating the free amine portion of resulting peptide with BSA overnight in $\mathrm{CH}_{2} \mathrm{Cl}_{2}$ prior to adding the amino acid fluoride one is able to effectively couple to highly hindered residues. ${ }^{18}$

However, another report states that although Fmoc amino acid fluorides are excellent reagents for coupling moderately hindered amino acids (e.g., Aib-to-Aib) they are not suited for significantly more hindered systems (e.g., Aib-to-MeAib). ${ }^{23}$ Coupling to the amino group of $N$ methylaminoisobutyric acid is at least an order of magnitude more difficult than coupling to its carboxyl function. ${ }^{23,24}$ While urethane-protected acid chlorides are inherently more reactive than the fluorides they are also ineffective for hindered systems due to complex oxazolone formation. $^{23}$ This limitation is bypassed if urethane protection is replaced by arenesulfonyl protection and the Aib-to-MeAib and even MeAib-to-MeAib couplings are easily achieved via the appropriate acid chlorides but not the acid fluorides. ${ }^{23}$

\section{Miscellaneous Couplings}

Amino acid fluorides have been shown to efficiently aminoacylate oligonucleotides (Scheme 4). ${ }^{25}$ 


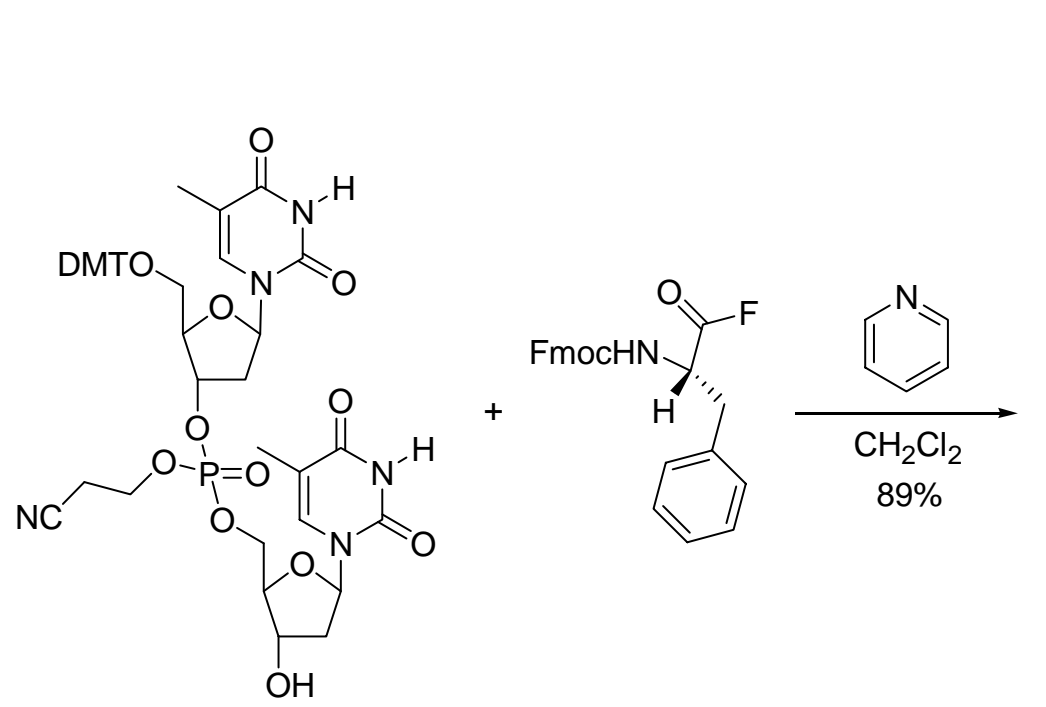

10

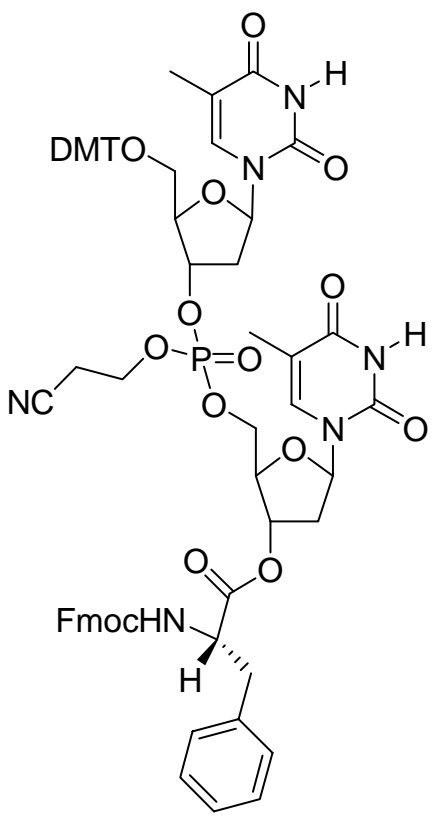

12

\section{Scheme 4}

The $\beta$-cyanoethyl group proved stable during the reaction of amino acid fluoride $\mathbf{1 1}$ with protected dinucleoside phosphate $\mathbf{1 0}$ providing compound $\mathbf{1 2}$ in good yield. ${ }^{25 a}$ As a result, any ribo- and deoxyribooligonucleotide, protected on the bases with Fmoc, and on the phosphates with the $\beta$-cyanoethyl group, could be easily aminoacylated. ${ }^{25 a}$

Amino acid fluorides have also been used in glycopeptide synthesis. ${ }^{26}$ Common to all types of N-linked glycoproteins is the presence of a $\beta$-configurated $\mathrm{N}$-glycosidic linkage between asparagine (Asn) and $N$-acetylglucosamine (GlcNAc) residues. ${ }^{26 a}$ This linkage was formed using two methods.

The first incorporated GlcNAc derived azide 13, which was reacted with properly protected fluorides, in the presence of Lindlar's catalyst and $\mathrm{Me}_{3} \mathrm{SiOMe}$ (to trap $\mathrm{HF}$ ) under $\mathrm{H}_{2}$ to afford the desired glyco-amino acid products 15 in 88-93\% yield (Scheme 5). ${ }^{26 a}$ The second method used a Boc-protected glycosylamine derivative 16, which was converted to the corresponding silyl carbamate 17, and then reacted with the desired amino acid fluoride in the presence of a catalytic amount of tetrabutylammonium fluoride to afford glycol-amino acid $\mathbf{1 5}$ in $78-87 \%$ yield. ${ }^{26 a}$ The above methods were applied to more functionalized systems using trisaccharide systems with similar success. $^{26 a}$ 


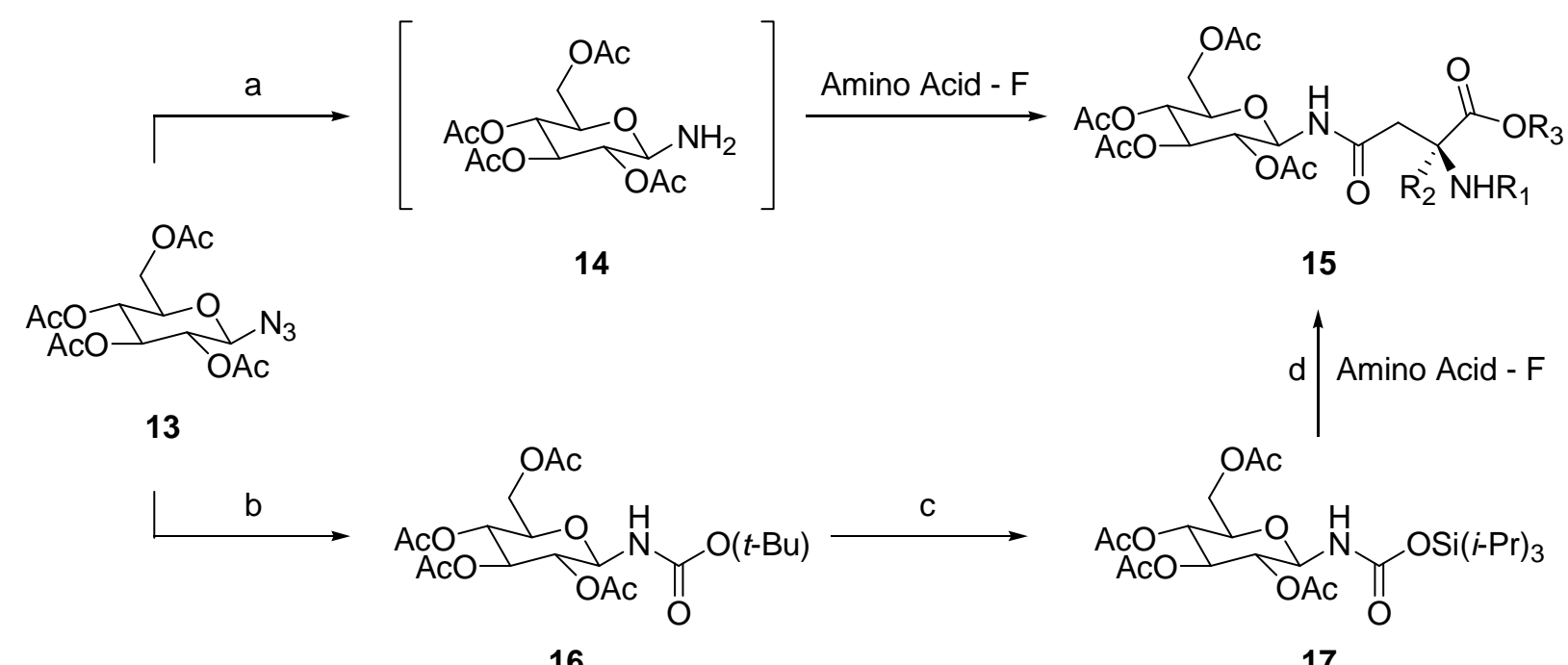

Scheme 5. Reagents and Conditions: (a) Lindlar's cat., $\mathrm{Me}_{3} \mathrm{SiOMe}, \mathrm{H}_{2} / \mathrm{THF}$ or $\mathrm{i}$-PrOH; (b) Lindlar's cat., $\mathrm{H}_{2}$, Boc $2 \mathrm{O} / \mathrm{EtOH}, \mathrm{rt}, 20 \mathrm{~h}, 87 \%$; (c) (i-Pr) ${ }_{3} \operatorname{SiOTf}\left(1.5\right.$ eq), DBMP (1.7 eq.) $/ \mathrm{CH}_{2} \mathrm{Cl}_{2}$, rt, $40 \mathrm{~min}, 100 \%$; (d) $\mathrm{Bu}_{4} \mathrm{NF}(0.2 \mathrm{eq}) / \mathrm{CH}_{2} \mathrm{Cl}_{2} .{ }^{26 \mathrm{a}}$

\section{Appendix}

Abbreviations not cited in the text: Aib, $\alpha$-aminoisobutyric acid; Boc, tert-butoxycarbonyl; BTFFH, bis(tetramethylene)fluoroformamidinium hexafluorophosphate; DBMP, 2,6-di-t-butyl4-methylpyridine; Deg, $\alpha, \alpha$-diethylglycine; DIPEA, diisopropylethylamine; DMF, $N, N-$ dimethylformamide; DMT, dimethoxytrityl; Fmoc, 9-fluorenylmethoxycarbonyl; HATU, $N$ [(dimethylamino)- $1 H$-1,2,3-triazolo[4,5-b]pyridine-1-ylmethylene]- $N$-methylmethanaminium hexafluorophosphate $N$-oxide; HBTU, $N$-[(1H-benzotriazol-1-yl)-(dimethylamino)methylene $]-N$ methylmethanaminium hexafluorophosphate $N$-oxide; HOAt, 1-hydroxy-7azabenzotriazole; Iva, isovaline; NMe-Aib, $N$-methyl Aib; NMe-Gly, $N$-methyl glycine; NMe-Val, $N$-methyl valine; PTF, benzyltriphenylphosphonium dihydrogen trifluoride; TFFH, tetramethylfluoroformamidinium hexafluorophosphate; Z, benzyloxycarbonyl.

\section{Acknowledgements}

I gratefully acknowledge Drs. Chi-Hsin Richard King, Keith D. Barnes, Michelle L. Pilato, Michael A. Guaciaro, Jolicia F. Gauuan, Larry Yet, and Kevin Fitzpatrick of Albany Molecular Research, Inc. for reviewing this document prior to submission. 


\section{References}

1. Fischer, E.; Otto, E. Ber. 1903, 36, 2106.

2. 2. Carpino, L.A.; Cohen, B.J.; Stephens, K.E.; Sadat-Aalee, D.; Tien, J.H.; Landridge, D.C. J. Org. Chem. 1986, 51, 3732.

3. Bertho, J-N.; Loffet, A.; Pinel, C.; Reuther, F.; Sennyey, G. Tetrahedron Lett. 1991, 32, 1303.

4. Olah, G.A. J. Org. Chem. 1961, 26, 225.

5. Rajeswari, S.; Jones, R.J.; Cava, M.P. Tetrahedron Lett. 1987, 28, 5099.

6. Carpino, L.A.; El-Faham, A. J. Am. Chem. Soc. 1995, 117, 5401.

7. El-Faham, A. Chemistry Lett. 1998, 671.

8. Rowell, R.M. Appl. Biochem. Biotechnol. 1984, 9, 447. (b) Oustrin, M.L.; Moisand, C.; Cros, M.L.; Bonnefaux, J. Ann. Pharm. Fr. 1972, 30, 685. (c) Moisand, A.; Moisand, C.; Pitet, G. Ann. Pharm. Fr. 1970, 28, 575.

9. Carpino, L.A.; Ionescu, D.; El-Faham, A.; Beyermann, M.; Henklein, P.; Hanay, C.; Wenschuh, H.; Bienert, M. Organic Lett. 2003, 5, 975.

10. (a) Carpino, L.A.; Mansour, E-S M.E.; Sadat-Aalaee, D. J. Org. Chem. 1991, 56, 2611. For a discussion of $N, N$-bis(alkoxycarbonyl) amino acids see (b) Carpino, L.A.; Mansour, ElSayed M.E.; El-Faham, A. J. Org. Chem. 1993, 58, 4162. (c) Savrda, J.; Chertanova, L.; Wakselman, M. Tetrahedron 1994, 50, 5309.

11. (a) Carpino, L.A.; Sadat-Aalaee, D.; Chao, H.G.; DeSelms, R.H. J. Am. Chem. Soc. 1990, 112, 9651. (b) Carpino, L.A.; El-Faham, A. J. Am. Chem. Soc. 1995, 117, 5401. TFFH has proved useful for segment condensations providing 1 equiv. of HOAt was present in order to preclude extensive epimerization. (c) Ingenito, R.; Dreznjak, D.; Guffler, S.; Wenschuh, H.; Organic Lett. 2002, 4, 1187. (d) Sakamoto, K.; Nakahara, Y.; Ito, Y. Tetrahedron Lett. 2002, 43, 1515.

12. Carpino, L.A.; El-Faham, A.; Minor, C.A.; Albericio, F.J. J. Chem. Soc., Chem. Commun. 1994, 201.

13. Bayer, E. Angew. Chem. 1991, 103, 117 and references cited therein; Angew. Chem., Int. Ed. 1991, 30, 113.

14. Wenschuh, H.; Beyermann, M.; Rothemund, S.; Carpino, L.A.; Bienert, M.; Tetrahedron Lett. 1995, 36, 1247.

15. (a) Bertho, J.-N.; Loffet, A.; Pinel, C.; Reuther, F.; Sennyey, G. Tetrahedron Lett. 1991, 32, 1303. (b) Wenschuh, H.; Beyermann, M.; Krause, E.; Brudel, M.; Winter, R.; Schumann, M.; Carpino, L.A.; Bienert, M. J. Org. Chem. 1994, 59, 3275.

16. Granitza, D.; Beyermann, M.; Wenschuh, H.; Haber, H.; Carpino, L.A.; Trutan, G.A.; Bienert, M. J. Chem. Soc., Chem. Commun. 1995, 2223.

17. Wenschuh, H.; Beyermann, M.; Haber, H.; Seydel, J.K.; Krause, E.; Bienert, M.; Carpino, L.A.; El-Faham, A.; Albericio, F. J. Org. Chem. 1995, 60, 405. 
18. Wenschuh, H.; Beyermann, M.; Winter, R.; Bienert, M.; Ionescu, D.; Carpino, L.A. Tetrahedron Lett. 1996, 37, 5483.

19. (a) Sammes, P.G.; Weller, D.J. Synthesis 1995, 1205. (b) Carpino, L.A.; Chao, H.G. J. Org. Chem. 1991, 56, 2635.

20. Wenschuh, H.; Beyermann, M.; El-Faham, A.; Ghassemi, S.; Carpino, L.A.; Bienert, M. J. Chem. Soc., Chem. Commun. 1995, 669.

21. Rajeswari, S.; Jones, R.J.; Cava, M.P. Tetrahedron Lett. 1987, 28, 5099.

22. Kim, H.-O.; Gardner, B.; Kahn, M. Tetrahedron Lett. 1995, 36, 6013.

23. Carpino, L.A.; Ionescu, D.; El-Faham, A.; Henklein, P.; Wenschuh, H.; Beyermann, M. Tetrahedron Lett. 1998, 39, 241.

24. Leplawy, M.T.; Jones, D.S.; Kenner, G.W.; Sheppard, R.C. Tetrahedron Lett. 1990, 11, 39.

25. (a) Oliver, J.S.; Oyelere, A.K. Tetrahedron Lett. 1997, 38, 4005. (b) Oliver, J.S.; Oyelere, A.K. J. Org. Chem. 1996, 61, 4168.

26. (a) Ito, Y.; Gerz, M.; Nakahara, Y. Tetrahedron Lett. 2000, 41, 1039. (b) Sasikumar, P.G.; Kumar, K.S.; Arunan, C.; Rajasekharan Pillai, V.N. J. Chem. Soc., Perkin Trans. I 2002, 2886.

\section{Authors' biographical data}

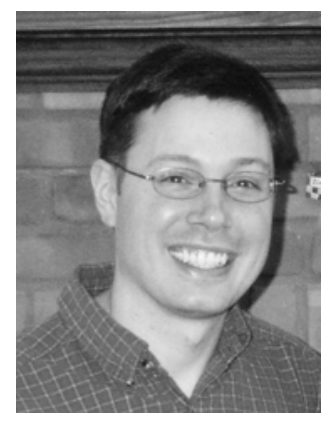

Dr. Lippert was born on March 25, 1972. He received his BA degree in 1994 from the University of Southern Maine in chemistry. Then in 1999 he received his Ph.D in organic chemistry at Arizona State University under the supervision of Professor George R. Pettit, where he worked on the synthesis of natural product anticancer agents at the Cancer Research Institute (CRI). Dr. Lippert was involved in the development of a potent vascular targeting agent, the combretastatin A-1 prodrug, which is now in Phase I clinical trials in England. After a one year postdoctoral assignment at the CRI, where he continued working on the synthesis of anticancer agents, he joined the Medicinal Chemistry Department at Albany Molecular Reseach, Inc. (AMRI) in Albany, NY. While at AMRI, Dr. Lippert has worked mainly on CNS and oncology projects. His research interests include the synthesis of natural products, peptides, peptidomimetics, and biologically active synthetic targets. 